\title{
Las nociones aristotélicas de naturaleza y de fin en Sobre la filosofía y en Física II
}

\author{
The Aristotelian notions of nature and \\ purpose in On philosophy and Physics II.
}

\author{
Claudia Seggiaro \\ Doutora em Filosofia pela Universidade de Buenos Aires e \\ pesquisadora do CONICET
}

Resumen: En el presente trabajo nos interesa analizar la relación entre naturaleza y fin, poniendo principal énfasis en el libro II de la Física y en Sobre la filosofía. Para ellos dividiremos el trabajo en tres partes. En la primera, examinaremos los posibles motivos por los cuales Aristóteles en Física II realiza la remisión a Sobre la filosofía. En la segunda parte y en la tercera, nos centraremos en dos fragmentos de Sobre la filosofía que creemos centrales para analizar las nociones de naturaleza y finalidad: el 8b y el 16. El objetivo de este análisis es establecer qué tipo de continuidad doctrinal hay entre la Física y Sobre la filosofía.

Palabras claves: Naturaleza; Fin; Aristóteles; Principio del movimiento.

Abstract: In the present work we are interested in analyzing the relation between nature and end, placing emphasis on book II of Physics and On Philosophy. For them, we will divide the work into three parts. In the first, we will examine the possible reasons why Aristotle in Physics II makes the remission to On Philosophy. In the second and the 
third part, we will focus on two fragments of On the philosophy that we think are central to analyze the notions of nature and end: $8 \mathrm{~b}$ and 16. The objective of this analysis is to establish what kind of doctrinal continuity there is between Physics and On Philosophy.

Keywords: Nature; End, Aristotle; Principle of movement.

La relación entre las nociones de naturaleza y finalidad es central en la Física de Aristóteles. Allí, en II 2 194a27-36, Aristóteles sostiene que la naturaleza es fin (télos) y "aquello con vistas a" (hoû héneka). Desde la perspectiva del Estagirita, "naturaleza" es tanto la forma como la materia. En función de esta definición de phýsis, en este capítulo Aristóteles se cuestiona cuál es el objeto de la física. Recurriendo a la analogía con las técnicas, concluirá, que, así como corresponde al constructor no solo conocer la forma del objeto que piensa construir, sino también su materia, en relación con los entes naturales corresponde a una misma ciencia abocarse al estudio de la forma y de la materia. No obstante, finalizando el capítulo Aristóteles agrega que la física se debe ocupar también del fin de los entes naturales. La interconexión entre los diferentes objetos de la física- materia/ forma y finalidad- es explicada muy claramente por Simplicio en su comentario a la Física (301, 1-30). Allí, Simplicio indica que la materia y el cambio natural en los entes sensibles tienen a la forma como fin. Esta tesis supone, según Simplicio, dos premisas básicas: 1) el cambio natural es continuo y 2) la forma es un fin para el cambio continuo, el cual cesa cuando este se ha alcanzado. En este contexto el Estagirita realiza una remisión a Sobre la filosofía. Esta referencia nos induce a pensar que en Sobre la filosofía Aristóteles habría sistematizado estas nociones que luego serían centrales en sus llamados discursos físicos. Teniendo esto como telón de fondo, en el presente trabajo nos interesa hacer hincapié en la relación entre naturaleza y fin, poniendo principal énfasis en el libro II de la Física y en Sobre la filosofía. Para ellos dividiremos el trabajo en tres partes. En la primera, analizaremos los posibles motivos por los cuales Aristóteles en el pasaje de la Física realiza la remisión a Sobre la filosofía. En la segunda parte y en la 
tercera, examinaremos dos fragmentos de Sobre la filosofía que creemos centrales para analizar la noción de naturaleza y finalidad: el 8b y el 16. El objetivo de este análisis es establecer qué tipo de continuidad doctrinal hay entre la Física y Sobre la filosofía. Para ello nos valdremos también de algunos pasajes clave de los comentarios de la Física de Filópono y de Simplicio, esto es, de los comentadores que nos han trasmitido los fragmentos arriba mencionados de Sobre la filosofía.

\section{1- Física II 2, 194a27-36 a la luz de Sobre la filosofia}

El pasaje II 2, 194a27-36 de la Física suele citarse entre los fragmentos de Sobre la filosofía, siendo por esto uno de los testimonios más firmes de la unidad temática entre ambos escritos. Allí Aristóteles remite a su obra actualmente pedida del siguiente modo:

También corresponderá a la física conocer las dos naturalezas. También es tarea de la física conocer "aquello con vistas a", es decir, el fin y cuantas cosas son con vistas al fin. Pero la naturaleza es fin y causa final; en efecto, de aquellas cosas de las que el movimiento es continuo y hay un fin de su movimiento, este fin es no solo <el $>$ último término sino también la causa final. Por eso también el poeta burlonamente se vio inducido a decir: "tiene el fin para el que nació". En efecto, no pretende ser fin de cualquier término sino solo el mejor. Puesto que las técnicas también producen la materia- unas absolutamente, otras la adecuan a sus propósitos- nos serviremos de todo como si todas las cosas existiesen para nosotros. En efecto, en cierto sentido, también nosotros somos un fin, pues la finalidad tiene dos significados. Esta cuestión ya la hemos tratado en Sobre la filosofía (trad. Boeri levemente modificada). ${ }^{1}$

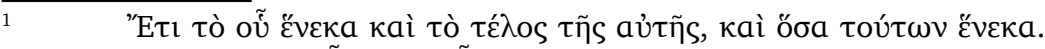

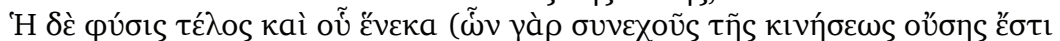

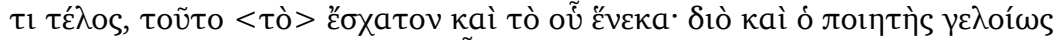

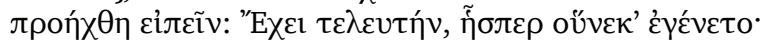

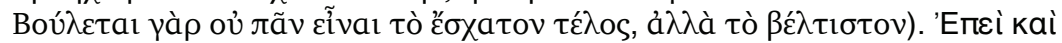

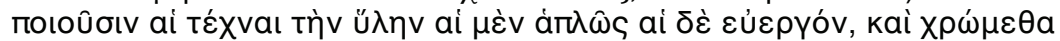

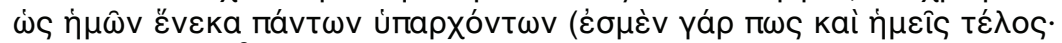

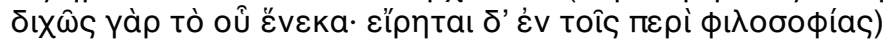


En consonancia con lo que indicamos en la introducción, en este pasaje Aristóteles señala que la física debe ocuparse de la naturaleza identificada con la forma y con la materia. Sin embargo, agrega que, debido a que la phýsis es también el fin o "aquello con vistas a" será objeto de la física también indagar la finalidad de la naturaleza. En relación con esto remite a su obra perdida, Sobre la filosofía. No obstante, por el estado fragmentario del texto, es complejo establecer a qué se puede estar refiriendo Aristóteles. Tanto Simplicio (Comentario a la Física de Aristóteles 304.1) como Temistio (Comentario a la Física de Aristóteles 43.3.) consideran que esta remisión a Sobre la filosofía es una alusión a los escritos éticos, sobre todo a la Ética Nicomáquea. Según Simplicio, Aristóteles realiza la distinción entre dos tipos de finalidad trazada en la Ética Nicomáquea. Desde la perspectiva de este último comentador, "< Aristóteles $>$ llama $<$ a esta obra $>$ "Sobre la filosofía", diciendo que la totalidad de los estudios sobre ética es verdaderamente llamada "filosofía" (Simplicio Comentario a la Física de Aristóteles 304,1 2-5). Sin embargo, no menciona un pasaje preciso de la Ética. Los estudiosos del comentario conjeturan que podría tratarse de Ética Nicomáquea I 1, 1094a 3-6, pasaje en el cual se equipara la noción de bien con la de fin, aunque no se desarrolla explícitamente un doble sentido de finalidad (Fleet, 2014, p.172). Los intérpretes modernos suelen obviar la referencia a Sobre la filosofía, obra en relación con la cual solo destacan que es un escrito aristotélico en forma de diálogo. Para la interpretación del pasaje de la Física, suelen remitir a Sobre el alma, ${ }^{2}$ más específicamente II 4, 415b2. ${ }^{3}$ Quienes siguen esta línea interpretativa, que no carece de fundamento, sostienen que Aristóteles está pensando en los siguientes sentidos de causa final: 1) finalidad como aquello "con vistas a", esto es, aquello en función de lo cual se hace algo o aquello que motiva la acción y 2) "el para quien", es decir, la persona sobre la que recae ese fin. El ejemplo que pone Simplicio (Comentario a la Física 303,1) es el siguiente: mientras para el médico la salud es su fin, en tanto que es el principio por él perseguido, el $2 \quad$ Boeri, 1993, p.177, Echandía, 1995, p.139 y Radice, 2011, p. 774. $3 \quad$ Sobre el alma (II 4, 415b2): "aquello en vista de lo cual" [se dice] de dos maneras: "aquello con vistas a" y "aquello en vista de quien". En Metafísica XII7,1072b2 "aquello para lo cual es "para bien de algo", y "con vistas a algo". 
hombre también es un fin, pues es en función de este último por quien busca la salud. La lectura de algunas obras que forman parte del corpus, como por ejemplo Metafísica XII 7, 1072b2 y La generación de los animales II 742a22, nos permite conjeturar que esta distinción era recurrente dentro del análisis de la causa final. Sin embargo, la referencia a esta distinción en Sobre la filosofía es mucho más problemática, pues no tenemos fragmentos que permitan afirmar que Aristóteles la haya sistematizado. Es relevante destacar que en el texto griego no dice que sobre estos sentidos de finalidad se ha explayado en Sobre la filosofía. Lo que señala Aristóteles es que esto ha sido abordado en Sobre la filosofía. El "esto" vuelve al texto más ambiguo de lo que algunas traducciones dejan entrever: ${ }^{4}$ Puede ser que Aristóteles esté haciendo referencia a los dos sentidos de finalidad, puede ser una alusión al carácter final de la forma, a la interconexión entre la noción de phýsis y la causa formal o, lisa y llanamente, puede ser una referencia a que todas estas cuestiones que venían siendo desarrolladas fueron tratadas en extenso en Sobre la filosofía.

La noción de phýsis es escasamente abordada en los fragmentos conservados de Sobre la filosofía. Aparece en el fragmento 9, en el contexto de la crítica a la tesis inmovilista de los eléatas, en donde tiene el sentido de "principio de movimiento". Vuelve a aparecer en la serie de fragmentos $27 \mathrm{a}-\mathrm{d}$, en los cuales se tiende a relacionar "elemento constitutivo" con "phýsis", razón por la cual se podría decir que ambas nociones tienden a ser equiparadas. "Phýsis" también aparece en dos

Echandía (1995): "porque somos en cierta manera también un fin, pues 'para lo cual' lo decimos en dos sentidos, como se indicó en Sobre la filosofía". Charlton (2006): "As was said in the De philosophia, there are two sorts of thing which a thing may be said to be for". Vallejos campos (2005): "ya que también nosotros en cierta forma constituimos un fin: pues el 'para qué' puede entenderse en dos sentidos, como se ha dicho en los libros Sobre la filosofía".

5 En el fragmento 27b, Cicerón le atribuye a Aristóteles la creencia de que junto a los cuatro géneros de principios Aristóteles postula una quinta naturaleza. El hecho de que la califique de "quinta", indica que esta naturaleza es otro principio junto con los cuatro géneros mencionados, razón por la cual marca la equiparación entra ambos términos: genera principiorum y natura. Dada su ambigüedad, es difícil determinar a qué concepto aristotélico se refiere Cicerón con la expresión "cuatro géneros de principios": si son los cuatro elementos o los cuatro tipos de causas. Dado el contexto de la argu- 
oportunidades en el fragmento 22e. En la primera aparición, Apuleyo (Sobre el dios de Sócrates VIII 137-138) cita o interpreta a Aristóteles diciendo: "como si la naturaleza estuviera dividida en cuatro grandes partes", a partir de lo cual se mencionan a los seres vivos que pertenecen a la tierra, al agua y al fuego. Al igual que en el fragmento 27b, aquí el término phýsis parece tener el sentido de elemento constitutivo. En este punto se debe tener en cuenta que para Aristóteles un elemento puede ser principio, pero no todo principio es un elemento. Esto es relevante, porque más adelante, al analizar el fragmento $8 \mathrm{~b}$, veremos que allí el sentido de phýsis no será este sino el de principio en el sentido de configuración conceptual.

En el contexto de la segunda aparición del término, Apuleyo se cuestiona: “¿por qué iba la naturaleza a permitir que solo este cuarto elemento del aire, que ocupa un espacio tan enorme, quedara desprovisto de todo y abandonado por todos sus habitantes, sin generar en él animales etéreos, igual que se generan animales flámeos en el fuego, acuáticos en el agua o terrígenos en la tierra?" (trad. Vallejo Campos). En esta nueva aparición, el significado de phýsis parece haber sufrido un desplazamiento. Allí, la naturaleza no es un elemento constitutivo, sino el principio teleológico que determina como está constituido lo real. Por tal motivo, aunque no podamos afirmarlo categóricamente, esto podría ser visto como un esbozo

mentación estamos inclinados a pensar que la primera opción es la más aceptable, motivo por el cual indirectamente se está calificando a la naturaleza como elemento constitutivo. Según Cicerón, este quinto elemento o principio no tiene para Aristóteles un nombre. No obstante, al decir esto, señala que el alma es un movimiento continuo, razón por la cual Aristóteles la denomina endelécheia. La vinculación entre esta descripción del alma y esta quinta naturaleza nos induce a pensar que Cicerón está queriendo indicar que, desde la perspectiva aristotélica, esta última es calificada indirectamente como un principio de movimiento. Como lo indica Vallejo Campos (2005, p. 319) el término endelécheia hace referencia al carácter continuo e imperecedero del movimiento que Cicerón atribuye al alma. No obstante, es importante notar lo que Zanatta (2008, p. 646) remarca: dicho término no es utilizado por Aristóteles. No aparece en el corpus ni es registrado por el index de Bonitz ni el lexicon de Radice. Pese a ello, la tesis de que el alma está en movimiento es una idea aristotélica que aparece incluso en la Física, en donde se describe la opinión y la imaginación como movimientos del alma, siendo que a su vez son facultades del alma (VIII 3, 254a26-30). 
de la concepción teleológica de la naturaleza presentada por Aristóteles en la Física. Cabe destacar que este fragmento no aparece en la mayoría de las ediciones y traducciones consultadas. Los estudiosos que lo incluyen son Jaeger (1993, p. 171), argumentando que las palabras de Apuleyo no pueden ser una referencia a la Historia de los animales, Vallejo Campos (2005, p. 308), y Untersteiner (1963, pp. 44-45), quienes en parte retoman el argumento del primero.

En Sobre la naturaleza de los dioses II 16, 44 (fragmento 21b), Cicerón señala que para Aristóteles "todo lo que se mueve, se mueve por naturaleza, por una fuerza o voluntariamente". Este pasaje tiene reminiscencias de la serie de fragmentos 11-16 del Protréptico en donde Aristóteles, partiendo de esta misma distinción, sostiene que, si lo que es construido por medio de una técnica tiene una finalidad y un para qué, con más razón lo que es por naturaleza, pues la técnica imita a la naturaleza y la completa. Por otra parte, rememora el comienzo del primer capítulo del libro II de la Física, en el cual se distingue a los entes naturales del resto de las cosas, sosteniendo que solo los primeros tienen un principio de movimiento interno, al que se identifica con la naturaleza.

El recorrido hasta aquí nos deja entrever que, si bien las nociones de phýsis y finalidad no son recurrentes a lo largo de los fragmentos conservados de Sobre la filosofía, los extractos que nos han llegado nos permiten rastrear lo que podría haber sido la concepción aristotélica de la naturaleza en este escrito y nos permiten sostener que no hay un quiebre argumentativo respecto de la Física. No obstante, los fragmentos de Sobre la filosofía que resultan relevantes a la luz del pasaje de Física II 2, 194a26 -36 son los 8b y 16. En el primer fragmento, se identifica al conocimiento de los cuerpos en sí mismos y de la naturaleza como un tipo de sophía. ${ }^{6}$ Aunque no haya un análisis exhaustivo, en el fragmento $8 \mathrm{~b}$ el concepto de naturaleza cobra cierto protagonismo. En el fragmento 16, si bien no se habla expresamente de la naturaleza, se realiza una "sistematización" sobre la causa final y su relación con los entes naturales, con lo

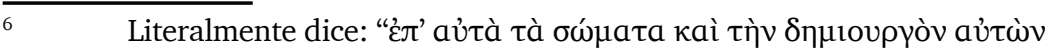

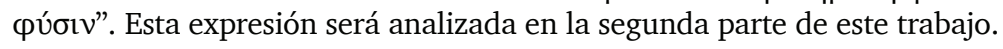


cual se puede decir que la phýsis es el concepto implícitamente supuesto a lo largo de todo el fragmento. El nexo entre estos dos fragmentos y Física II 2, 194a26-36 es relativamente claro, si tenemos en cuenta la tesis defendida por Aristóteles en el pasaje de la Física y el argumento por el cual Aristóteles lo defiende. Allí, Aristóteles identifica a la naturaleza con la causa final. Esta última tesis la infiere de tres premisas: dos enunciadas explícitamente y otra formulada implícitamente. Las dos primeras son: 1) el movimiento tiene un fin (II 2, 194a29) y 2) el fin es lo mejor (II 2, 194a32-33). La tercera premisa, la implícita, es que el fin de una cosa es su forma (II 1, 193b 18-19), razón por la cual constituye lo mejor. ${ }^{7} \mathrm{El}$ examen de los fragmentos $8 \mathrm{~b}$ y 16 nos permite identificar de manera expresa o solapada la presencia de estas premisas. En el fragmento 8 b, la premisa 1 se halla prefigurada en el carácter demiúrgico de la naturaleza, y la premisa implícita de Física II 2, 194a26 -36 está supuesta en la alternancia ousía y phýsis ${ }^{8}$ que aparece en el fragmento. La identificación entre la causa final y lo mejor, la segunda premisa explícita del pasaje citado de la Física, es el problema principal del fragmento 16 . No obstante, la lectura atenta del fragmento a la luz del comentario a la Física de Simplicio nos induce a pensar que también están operando las otras dos premisas. Creemos que estos dos fragmentos de Sobre la filosofía, y su relación con el fragmento 9 , nos permitirán entender por qué Aristóteles remite a esta obra en la Física. Por tal motivo, en lo que sigue nos centraremos en estos dos fragmentos de modo tal de establecer en qué medida las tesis en ellos presentadas se relacionan con las analizadas en el pasaje citado de la Física.

\footnotetext{
$7 \quad$ En Física II 8 199a 30-33: Aristóteles reafirma esta identificación: “y puesto que la naturaleza puede entenderse en dos sentidos, como materia y como forma, y dado que esta es el fin y todo lo demás es en vista de un fin, la forma debe ser causa final" (trad. Boeri).

$8 \quad$ Tal como lo veremos más adelante, mientras en la primera parte del fragmento, Filópono le adjudica a Aristóteles la identificación entre la sabiduría y el conocimiento de la ousía, hacia el final del fragmento, al determinar los estadios de la sophía, Filópono equipara a esta última con el conocimiento de la phýsis. La lectura de este fragmento a la luz de Física II 1-2 y Metafísica V 4 1014b35-ss., así como del comentario de Filópono a la Física nos induce a pensar que el referente de ousía y phýsis debe ser el mismo.
} 


\section{2.-Fragmento 8b y Física II: naturaleza como forma y movimiento con vistas a un fin}

El fragmento 8b es uno de los más extensos de los que nos han llegado de Sobre la filosofía. Dado esto, iremos citando lo extractos en los que se trata la noción de naturaleza o aquellos que son relevantes en relación con el tema del trabajo conforme vayamos haciendo nuestro análisis. En principio, cabe destacar que hacia el final del fragmento se señala:

Después, progresando en su andadura, llegaron a los cuerpos mismos y a la naturaleza que es artífice de éstos, y le dieron a ello el nombre más específico de teoría natural y a los que son versados en tales asuntos los llamaron sabios en cuestiones naturales. En quinto lugar, finalmente, trataron de las entidades divinas en sí mismas, supracósmicas y absolutamente inmutables y denominaron al conocimiento de éstas la sabiduría suprema (trad. De Vallejo Campos). ${ }^{9}$

El fragmento $8 \mathrm{~b}$ ha sido trasmitido por Filópono en el comentario a la Introducción a la aritmética de Nicómaco I, 3943. Esto es significativo, pues las palabras atribuidas al Estagirita no aparecen insertas en un comentario a su obra, sino en el contexto de su análisis de la teoría metafísica y epistemológica de un neopitagórico. El fragmento corresponde a un pasaje que prácticamente abre el comentario a la obra de Nicómaco. según Filópono, si bien para los antiguos pitagóricos la filosofía era amor a la sabiduría, el término "sabio" era usado para designar al experto en el dominio de cualquier técnica, ya sea la zapatería o la carpintería. Este uso del término sophós hace que, respecto a la noción de sophía, Filópono vincule el pensamiento

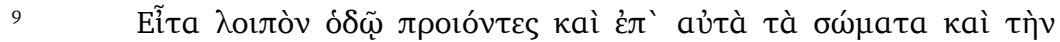

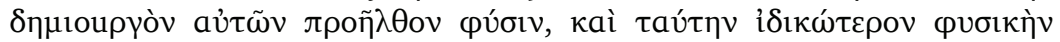

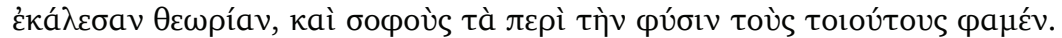

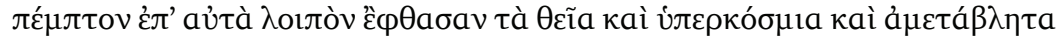

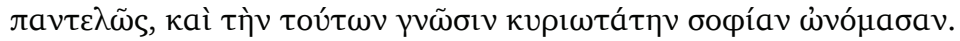

Si bien la identificación entre la física y cierta sabiduría no es atribuida directamente a Aristóteles, creemos que la última parte del fragmento $8 \mathrm{~b}$ es pertinente para nuestro trabajo ya que, tal como lo demostraremos en este apartado, la noción de phýsis como principio y causa allí supuesto es consistente con la concepción aristotélica de la naturaleza. En este sentido, la identificación entre la física con el conocimiento de las phýsis está en la órbita de lo que se puede considerar la concepción aristotélica de la física.
} 
de Nicómaco con el platonismo. Para él, con intenciones platónicas, Nicómaco buscaba el verdadero fin de la filosofía y los medios por los cuales acceder a él. En este contexto, identifica a la sabiduría como una especie de luz y claridad. Filópono cree encontrar esta misma concepción de raigambre platónica en Aristóteles, al que parafrasea o cita, sin especificar exactamente su fuente. Comentando a Tarán, Giardina (1999, p. 248) sostiene que la derivación sophía de saphía que hace Filópono en su comentario puede estar siendo retomada de la Metafísica de Aristóteles (993b 9-11), aunque, "según algunos, tal interpretación deriva de un fragmento de De philosophia de Aristóteles" (Giardina, 1999, p. 248), esto es, el 8b. En él, tras hacer alusión a que la civilización y, con ella, los conocimientos adquiridos por los hombres se han destruido y perdido cíclicamente, Filópono despliega las cinco acepciones de sophía atribuidas a los griegos, cada una de las cuales parece coincidir con un nivel en el progreso del conocimiento. En concordancia con Metafísica I 1, 981b20 y ss. ${ }^{10}$ Filópono señala que, satisfechas las necesidades básicas, los hombres comenzaron a adquirir conocimientos técnicos y científicos y, tras eso, el conocimiento relativo a la política y a las leyes, conocimiento al cual también calificaron de sabiduría. Los dos estadios subsiguientes son los detallados en el pasaje citado: 1) el conocimiento de los entes sensibles y 2) el de las entidades suprasensibles. Lo relevante a los fines de nuestro trabajo es lo referido por Filópono respecto del conocimiento de las entidades sensibles, pues es en relación con esto que trae a colación la noción de naturaleza. En cuanto a esto último nos interesan dos cosas. La primera es cómo Filópono presenta el primero de estos dos tipos de conocimiento. La segunda es por qué la naturaleza es calificada de demiourgós. En relación con la primera cuestión, Filópono sostiene que los hombres conocieron dos cosas: los cuerpos en sí mismos, pero también la naturaleza. Los términos utilizados por Filó-

$10 \quad$ Como lo resalta Vallejo Campos (2005, p. 276), en Metafísica 1 , $981 b 20$ y ss., "Aristóteles distingue tres etapas en el desarrollo de las artes y no cinco, como en este texto de Filópono: la creación de las artes destinadas a satisfacer las necesidades imprescindibles, en segundo lugar, las que sirven para la consecución del placer y, finalmente, la aparición de la ciencia en la que predomina el saber por el saber". 


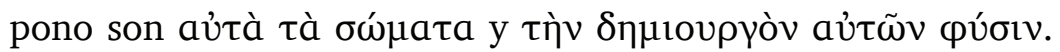
Esta distinción nos retrotrae a la primera parte del fragmento, donde Filópono sostiene:

ciertamente, dado que las cosas inteligibles y divinas, como dice Aristóteles, a pesar de ser clarísimas en virtud de su propia entidad, a nosotros nos parecen tenebrosas y confusas, por la niebla en la que el cuerpo nos envuelve, es natural que le diera el nombre de sabiduría a la ciencia que trae estas cosas a la luz para nosotros (la Introducción a la aritmética de Nicómaco I, 9- 14. trad. Vallejo Campos). ${ }^{11}$

Podemos ver que en este breve pasaje Filópono le atribuye a Aristóteles la contraposición entre la luz de lo inteligible y la oscuridad generada por el cuerpo. Esta distinción nos lleva a pensar que Filópono atribuye a Aristóteles dos modos de acceder a las entidades sensibles: tal como se nos aparecen y tal como son en sí mismas. ${ }^{12}$ Bajo el primer modo el hombre puede aprender el aspecto sensible de las cosas, sus características sensibles, pero no sus principios constitutivos. Para acceder a esto último, debe conocer las cosas "en virtud de su propia ousía". Alguien es sabio solo cuando conoce las cosas de este segundo modo, esto es, cuando conoce cómo las cosas están constituidas y, por ende, sabe cuál es su esencia ${ }^{13}$ o configuración conceptual. En el comentario a la Física 4. 34-5.1, Filópono sostiene:

$\mathrm{Si}$, por lo tanto, las cosas físicas son o cuerpos o tienen existencia en un cuerpo, y estas cosas son compuestas, entonces las cosas físicas son compuestas. Pero toda cosa compuesta tiene elementos y causas

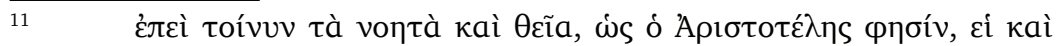

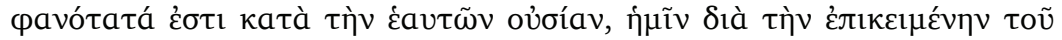

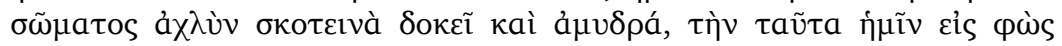

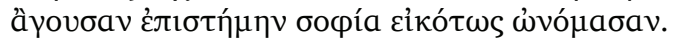

12 Vallejo Campos advierte que "para Wilpert ("Die Stellung der Schrift Uber die Philosophie ...”, págs. 155-162) el uso de autá (cuerpos en sí mismos, entidades divinas en sí mismas) es un signo del platonismo que Aristóteles aún profesaba en la obra, en la que el saber es determinado por su objeto" (2005, p. 276). Al igual que Vallejo Campos (2005, p. 276), no creemos que esto sea incompatible con el concepto de sophía que Aristóteles introducirá en la Metafísica y que defiende en esta obra. Véase Berti, 1997, p.265.

13 En el fragmento 35 del Protréptico Aristóteles homologa causas y ousía. Solo hay conocimiento en sentido estricto cuando se produce el develamiento de ambas cosas. 
y principios: pues las cosas simples son los elementos de las cosas compuestas. Por lo tanto, las cosas tienen principios y causas. Así es como Teofrasto apoya la premisa menor. Para sumar a esto la premisa mayor (que cada cosa que tiene principios o causas o elementos llega a ser conocida cuando ellos han llegado a ser conocidos), él saca así la conclusión de que las cosas físicas llegan a ser conocidas cuando se han conocido sus principios. ${ }^{14}$

Este pasaje es relevante por dos motivos. El primero está relacionado con qué entiende Filópono por cuerpo. En relación con esto, en la primera parte, Filópono parece suponer la distinción entre elementos y sustancia sensible. La alusión a los elementos se desprende de la distinción entre cosas que son cuerpo o están en un cuerpo. Las cosas que solo son cuerpos tienen dos características: 1) son simples y 2) son los elementos materiales en base a los cuales llegan a ser las restantes cosas, razón por la cual o bien pueden ser los cuatro elementos (agua, fuego, aire y tierra) o es el substrato material. Las cosas compuestas no parecen recibir este calificativo solo porque lleguen a ser a partir de la combinación de los cuerpos simples. Esto se desprende de lo siguiente: si hay una entidad que está en un cuerpo, pero no se identifica con él, puede ser corpórea sin serlo enteramente o, incluso, puede no ser corpórea. Esto se confirma unas líneas más abajo. Allí Filópono dice que un compuesto tiene elementos, principios y causas. Esta descripción nos lleva a inferir que los compuestos son las entidades sensibles descriptas en Física II y que llegan a ser por la intervención de cuatro causas: 1) la material: "aquello a partir de lo cual"; 2) la formal: "el qué es"; 3) la eficiente: "aquello por lo cual" y 4) la final: "aquello con vistas a". De esto se desprende que, al referirse a los cuerpos en sí mismos en el pasaje de la Introducción a la aritmética de $\mathrm{Ni}$ cómaco Filópono puede estar aludiendo a los cuerpos simples, a los compuestos, o a ambos simultáneamente.

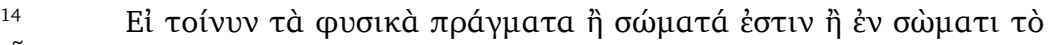

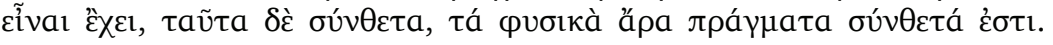

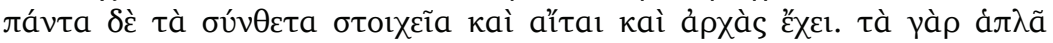

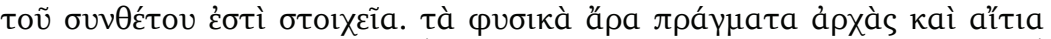

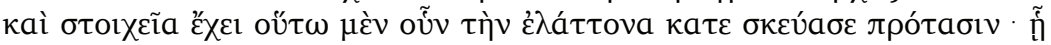

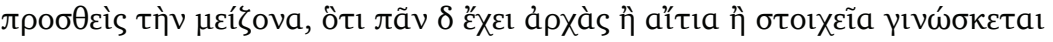

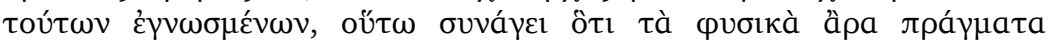

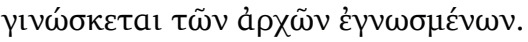


El otro punto relevante es que en el pasaje citado del comentario a la Física Filópono sostiene que solo conocemos los cuerpos compuestos cuando aprehendemos sus causas. Pese a que en este pasaje Filópono no realiza explícitamente la vinculación entre estos principios- causas y la ousía, si leemos el comentario de la Física a la luz del pasaje del comentario a la Introducción a la aritmética de Nicómaco que nos ha llegado como fragmento $8 \mathrm{~b}$, podremos notar que dicha relación parece estar operando implícitamente. Si por el pasaje del comentario a la Física debemos concluir que conocemos las entidades sensibles cuando conocemos sus principios y causas, pero, paralelamente, debemos admitir que, tal como se indica en el comentario a la Introducción a la aritmética de Nicómaco, sabemos que son las cosas cuando aprehendemos su ousía, debemos concluir que hay una interconexión entre los principios y causas de las cosas y su ousía. De la formulación de ambas tesis se deprende que conocer las causas y los principios implica conocer la ousía de la cosa. Ahora bien, la ousía no parece ser otra cosa que lo que hacia el final del fragmento 8b Filópono identifica con la naturaleza, razón por la cual quien conoce la ousía de algo conoce por esto mismo su naturaleza. ${ }^{15}$ Pese a que Filópono no hace la identificación expresamente, esta resulta evidente a la luz de la afirmación realizada por el neoplatónico en la primera parte del fragmento $8 \mathrm{~b}$, citada más arriba, pero que volveremos a citar por cuestiones de practicidad. Allí Filópono decía:

ciertamente, dado que las cosas inteligibles y divinas, como dice Aristóteles, a pesar de ser clarísimas en virtud de su propia entidad, a nosotros nos parecen tenebrosas y confusas, por la niebla en la que el cuerpo nos envuelve, es natural que le diera el nombre de sabiduría a la ciencia que trae estas cosas a la luz para nosotros (la Introducción de la aritmética de Nicómaco I 1. trad. Vallejo Campos)

$15 \quad$ Metafísica V 5, 1015a 13-17. Aristóteles afirma: "naturaleza, primariamente y en el sentido fundamental de la palabra, es la sustancia de aquellas cosas que poseen el principio del movimiento en sí mismas por sí mismas. En efecto, la materia se denomina naturaleza porque es capaz de recibir aquella, y las generaciones y el crecimiento porque son movimientos que se originan

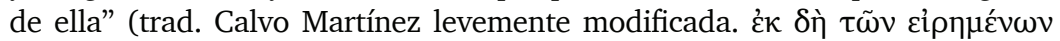

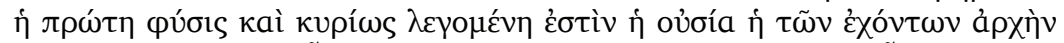

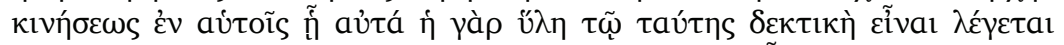

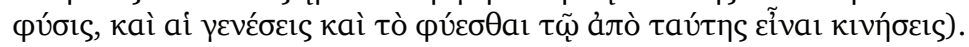


La lectura del fragmento en su conjunto nos permite concluir que en la preposición "a pesar de ser clarísimas en virtud de su propia entidad" y en la oración de la última parte del fragmento "llegaron a los cuerpos mismos y a la naturaleza que es artífice de éstos", ${ }^{16}$ ousía y phýsis deben ser equivalentes para que la unidad del argumento sea sostenible. Si, por la primera parte del fragmento $8 \mathrm{~b}$ conocer algo es conocer su ousía, y por el comentario de la Física, sabemos que esto implica buscar sus causas y principios, para que la física pueda ser conocimiento en sentido estricto, debe serlo de esto último. Como consecuencia de esto, phýsis en el fragmento 8b debe ser la ousía mencionada en la primera parte del pasaje o debe ser algunos de los principios y causas de los cuales habla Filópono en su comentario a la Física.

La segunda cuestión que, como indicamos más arriba, nos interesa del fragmento 8b de Sobre la filosofía es el uso de sustantivo demiourgós aplicado a la naturaleza. La presencia de esta palabra nos sugiere la idea de un tipo de causalidad. Dado esto, la pregunta que surge es: ¿qué tipo de causalidad cree Filópono que Aristóteles le adjudica a la naturaleza al describirla de este modo? En el comentario a la Física 6. 4-5, Filópono sostiene que para Aristóteles:

La naturaleza no construye los primeros elementos por medio de algún instrumento, sino que ella los crea directamente de la materia y de la forma. ${ }^{17}$

El verbo utilizado por Filópono para referirse a cómo opera la naturaleza es demiurgế. Se debe recalcar que este verbo referido a la naturaleza no es frecuente en el corpus aristotélico, pero se halla atestiguado en algunos escritos, sobre todo, en los tratados biológicos. En Partes de los animales I 5, 645a9 Aristóteles usa el participio aoristo demiourgésasa, para refe-

\footnotetext{
16 En esta parte del fragmento, en el contexto del análisis del "desarrollo histórico" de la sophía, se describe el cuarto estadio de la sabiduría, identificado con el conocimiento de los cuerpos en sí mismos y de la naturaleza como su artífice.

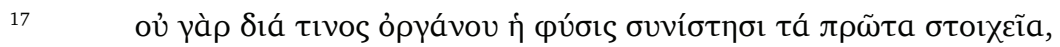

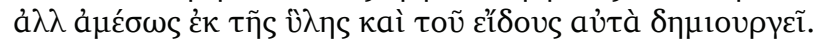


rirse a que la naturaleza es creadora de los seres sensibles. En esta misma obra en II 9, 654b32, utiliza el perfecto dedemioúrgeken, indicando que, al igual que los que moldean figuras, la naturaleza creó a los animales con cuerpos duros: huesos. Por otra parte, en el primer capítulo de Las partes de los animales, para referirse a la generación Aristóteles utiliza diversas formas verbales derivadas de poiéo. Según Lennox (2001, p. 190), pese a que Aristóteles suele explicar el operar de la naturaleza realizando analogías con las técnicas, no hay motivo para considerar que el Estagirita concibe a la naturaleza como un hacedor y, por lo tanto, como la contrapartida del demiurgo platónico. Desde la perspectiva de este autor, la naturaleza como agente solo refiere a la naturaleza como forma, así como su tendencia hacia un fin. Para Golitsis (2008, p. 45), esta manera de describir la phýsis está relacionada con el hecho de que, según los peripatéticos, la naturaleza es identificada con la causa productiva y final de las cosas. Simplicio interpreta la concepción aristotélica de la naturaleza de manera parecida:

Puesto que la naturaleza, que es en algún sentido la causa productiva inmediata de las realidades naturales, se mostrará que es principio de movimiento y que toda realidad natural, que es un cuerpo, posee en él su principio de movimiento, es necesario que los discursos físicos sean sobre el movimiento (Comentario a la Física de Aristóteles 3.25-27). ${ }^{18}$

Si bien Simplicio no utiliza el término demiourgós, se refiere a la naturaleza como una causa productiva, aítion poietikón, pues es principio de movimiento de los seres naturales. Retomando el comentario de Alejandro de Afrodisia, Simplicio (Comentario a la Física de Aristóteles 310, 20-311, 30) sostiene que la generación es una progresión ordenada de movimientos: un movimiento es seguido de forma ordenada por un segundo movimiento y así sucesivamente hacia el fin por cuya causa la cosa existe. Apelando a los dos modos de causalidad, la causa productora y la causa final, Simplicio diferencia estos dos momentos de la generación, en los cuales la naturaleza es al mis-

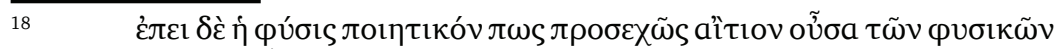

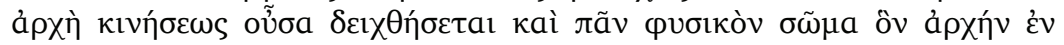

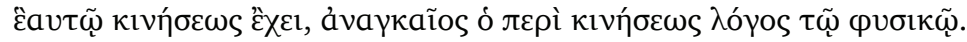


mo tiempo principio y fin del movimiento. Este doble aspecto de la phýsis puede ser remarcado por Simplicio, pues, tal como lo indica Aristóteles en II 1 193b 12, la phýsis es ella misma el camino (hodós) hacia la phýsis. Como consecuencia de esto, en Física II 2, 194a26-36 Aristóteles indica que corresponde a la física conocer la naturaleza y aquello "con vistas a", pues la causa final es aquello por lo cual el principio de movimiento se realiza. Al calificar a la naturaleza como demiurgós, Filópono podría estar pensando en este proceso, apelando a un calificativo que explica de manera metafórica cómo opera la phýsis en el proceso de generación. Desde esta perspectiva, la naturaleza en tanto demiurgo puede ser entendida como el aítion poietikón del cual habla Simplicio y, por lo tanto, como principio de movimiento que tiende hacia un fin.

En el fragmento 9 de Sobre la filosofía (Sexto Empírico Contra los profesores $X$ 45-46) Aristóteles afirma:

Unos, efectivamente, afirman que hay movimiento y otros que no ... Que no existe es lo que sostienen los seguidores de Parménides y Meliso, a los cuales Aristóteles ha llamado inmovilistas y negadores de la naturaleza, inmovilistas por la inmovilidad que defienden, y negadores de la naturaleza, porque ésta es principio de movimiento, lo cual fue suprimido por ellos al afirmar que nada se mueve (trad. Vallejo Campos).

Por este fragmento sabemos que para Aristóteles la naturaleza además de ser el principio constitutivo de una cosa es un tipo de movimiento. En este fragmento, de hecho, el Estagirita afirma que quienes, como los eléatas, niegan la existencia del movimiento, suprimen por este motivo la naturaleza. En la Física, más específicamente en II 8, 199b, 15-16, Aristóteles afirma:

Pues las cosas por naturaleza son aquellas que, movidas por un principio interno, llegan a un fin (trad. Boeri). ${ }^{19}$

Sobre la base de que las cosas que son producto del arte imitan a la naturaleza, ${ }^{20}$ el Estagirita concluye que, si las prime-

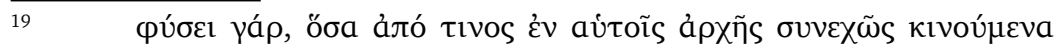
à

$20 \quad$ Protréptico fragmento 14. 
ras tienen una finalidad y un para qué, entonces las cosas que son por naturaleza deben realizarse conforme a un fin (Protréptico, fragmento 12). Para comprender esta tesis, se debe tener en cuenta que, según Aristóteles, todo llega a ser a partir del sustrato y de la forma. No obstante, desde la perspectiva aristotélica, en sentido propio phýsis es solo la forma. En Física II 2, 193a 36-193b5 señala: "la carne o el hueso en potencia no tienen aún su propia naturaleza ni son por naturaleza antes de adquirir su determinación conceptual específica, por medio de la cual establecemos la definición de carne o hueso. En este segundo sentido, por tanto, la naturaleza de los entes que en sí mismos poseen el principio de movimiento será la configuración y la forma, la cual no es separable a no ser conceptualmente" (trad. Boeri, levemente modificada). ${ }^{21}$ A esto se debe agregar que para el Estagirita la forma es la causa formal de los entes sensibles, ${ }^{22}$ pero también su causa final, pues dichos entes se realizan como tales cuando plenifican su forma. De la lectura del segundo libro de la Física se desprende que para Aristóteles la naturaleza tiene dos aspectos: es el fin de los entes naturales, en tanto se identifica con la forma, pero también es el proceso por el cual estos llegan a su plena realización. Citando a Quarantotto, podemos decir que "cualquier cosa que es un principio interno, si representa al mismo tiempo el principio de identidad (la forma) y la causa motriz del cual es principio y si determina un proceso del cual resulta una forma, que es dotada al mismo tiempo de una función motriz, que sea capaz de reiterar de manera circular y recursiva la misma dinámica: la forma se produce y reproduce a sí misma: un hombre genera a otro hombre" (Quarantotto, 2002, p. 160).

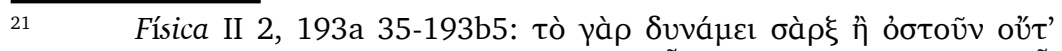

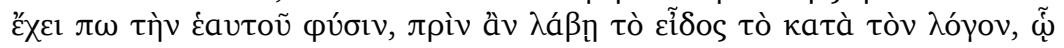

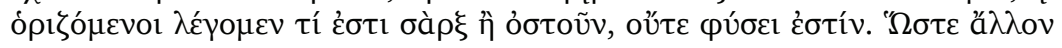

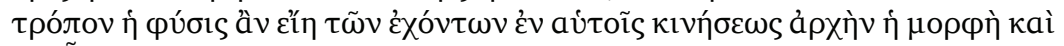

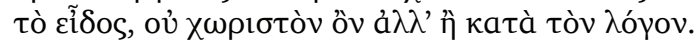

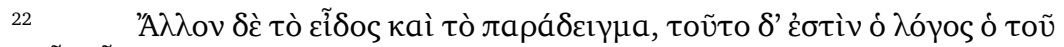

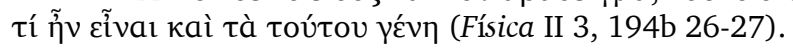


3 -Fragmento 16: finalidad y naturaleza en Sobre la Filosofía a la luz de Física II

En el fragmento 16 transmitido por Simplicio en su Comentario a Sobre el cielo (288. 28- 289.1-15), se le atribuye a Aristóteles lo siguiente:

Efectivamente, en general, en aquellas cosas en las que hay algo mejor, hay también algo óptimo. Así pues, dado que en las cosas que son hay algunas mejores que otras, habrá, por tanto, también una que sea óptima y ésta será lo divino. Ahora bien, lo que cambia lo hace por efecto de otra cosa o por sí mismo, pero si cambia por otra cosa, esta será mejor o peor, y si cambia por sí misma, el cambio será porque lo hace a otra cosa peor o porque aspira a una mejor, pero lo divino no tiene nada que sea mejor que sí mismo por efecto de lo cual pudiera ser cambiado (ya que esto sería más divino) y tampoco es lícito que lo mejor padezca por obra de lo que es peor. Ciertamente, si experimentara algún cambio por obra de lo que es peor, admitiría algo malo, mas no hay nada malo en él. Sin embargo, tampoco se cambia a sí mismo porque aspire a algo mejor, ya que no carece de ninguna de las perfecciones que le son propias. Verdaderamente, tampoco cambiará a peor, porque ni siquiera el hombre se hace peor voluntariamente a sí mismo, ni tiene nada malo, como habría admitido si hubiese experimentado un cambio a peor (trad. Vallejo Campos). ${ }^{23}$

Tal como lo indica, Golitsis (2008, p. 42), después de Alejandro de Afrodisia, la palabra "cielo" no significa el "cielo último", del cual hablaba Aristóteles, sino el mundo, tal como lo había tratado Platón en Timeo 28b 2-4: "el cielo todo entero o el mundo o cualquier otro nombre que le convenga mejor". De hecho, los escritos titulados tà aídia, eran vistos por los peripatéticos como parte de los discursos físicos. Al realizar sus comentarios, Simplicio presupone esta clasificación de los escritos,

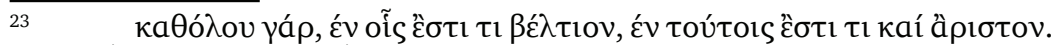

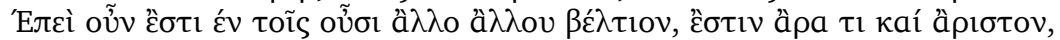

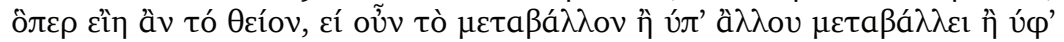

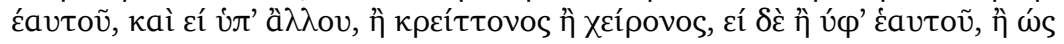

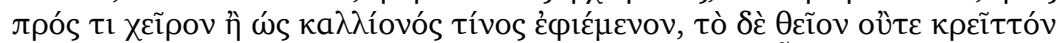

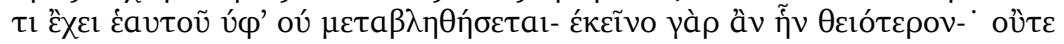

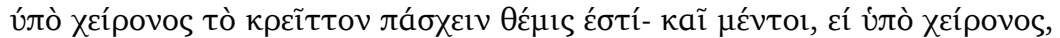

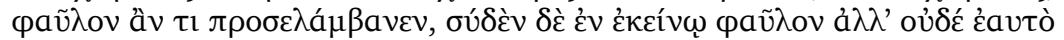

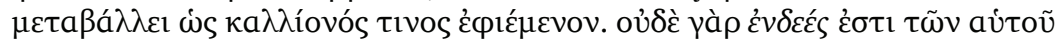

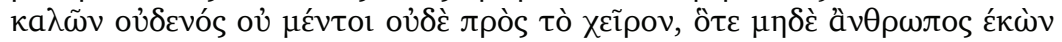

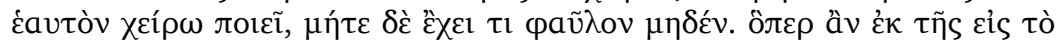

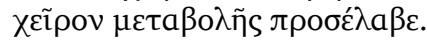


que los neoplatónicos tendieron a adoptar, razón por la cual es esperable que en su comentario a Sobre el cielo Simplicio presuponga las tesis que fueron tematizadas en su comentario a Sobre la física, pues Sobre el cielo y la Física no eran considerados tratados independientes, sino interrelacionados. Ahora bien, la referencia explícita a Sobre la filosofía en su comentario a Sobre el cielo nos permite conjeturar que Simplicio creía que había una continuidad en relación con las tesis defendidas en las tres obras.

Se debe tener en cuenta, por otra parte, que los comentarios de Simplicio a la obra de Aristóteles fueron escritos entre 532 y 540 d. C. Se tiene noticias de que, con anterioridad a la aparición de la edición de la obra aristotélica realizada por Andrónico de Rodas, los textos conocidos de Aristóteles eran los llamados exotéricos, dentro de los cuales estaba incluido Sobre la filosofía. Con posterioridad a esta edición, dichos textos comenzaron a perderse y ganaron protagonismo las obras esotéricas del Estagirita, dentro de las cuales estaban la Física y Sobre el cielo. La lectura de Simplicio de la obra perdida de Aristóteles debió de estar mediada por la interpretación del resto de las obras que comenzaron a ganar protagonismo. Baltuseen (2008, pp. 88-ss.) considera que Simplicio realiza sus comentarios a la obra aristotélica basándose en el trabajo y enseñanzas de los primeros peripatéticos, tales como Teofastro y Eudemo. El análisis de los diversos comentarios de Simplicio le permite decir que ha tenido acceso a la versión de la Física de Eudemo y a los trabajos Teofrasto. Esto metodológicamente tiene dos consecuencias: la primera es que sus fuentes son cercanas a Aristóteles y, en este sentido, lo aproximan más al pensamiento del Estagirita. Sin embargo, la segunda consecuencia está relacionada con el hecho de que, si bien los primeros peripatéticos tomaron a Aristóteles como punto de partida, no acordaban en todos los puntos con las concepciones aristotélicas. Las doctrinas peripatéticas no eran un cuerpo de conocimiento estático, sino un conjunto dinámico de concepciones, con lo cual que sus fuentes sean cercanas a Aristóteles nos es garantía de que reproduzcan por completo su pensamiento.

Bajo la premisa de que, si hay algo mejor, debe haber algo óptimo y esto será lo divino, en este fragmento, Simpli- 
cio le adjudica a Aristóteles una distinción entre dos tipos de entidades: aquellas sujetas a la corrupción y que se mueven por un fin y aquella otra que constituye un fin en sí mismo. Desde la perspectiva de Simplicio, para Aristóteles hay cosas que son mejores que otras, por lo tanto, se puede trazar una clasificación de las cosas según éstas sean mejores o peores. Lo divino está por encima de estas cosas, pues por sobre él nada puede ser mejor. Lo que resulta relevante a los efectos de nuestro trabajo es la tesis que Simplicio le adjudica a Aristóteles en relación con las cosas sujetas al devenir, pues presenta reminiscencias de las principales tesis defendidas por el Estagirita en Física II 1. Para Simplicio, entre las cosas que están sujetas al devenir, algunas tienen un principio interno de movimiento, mientras que otras se mueven a causa de otra cosa. Esta distinción realizada en Sobre la filosofía nos hace pensar que Aristóteles está diferenciado las sustancias sensibles de los artefactos. ${ }^{24}$ En ambos casos, requieren de una causa final por la cual moverse y una causa motriz, esto es, aquello que las mueva. La diferencia es que, mientras en el caso de las sustancias sensibles el principio de movimiento es interno, en el caso de los artefactos es externo. Desde la perspectiva aristotélica, "la naturaleza es cierto principio o, más precisamente, es causa del movimiento o del reposo en aquello en que es inherente en sentido primario por sí, es decir, no por accidente" (Física II 2, 192b 22-23. trad. Boeri). Un artefacto, como por ejemplo una cama, si bien está sujeto a la generación y la corrupción, no tiene un principio intrínseco de movimiento. Debe haber un individuo que lo piense e imprima en una materia determinada, madera, por ejemplo, la forma correspondiente o configuración conceptual. Las causas por las cuales llega a ser son externas y los motivos por los cuales se va deteriorando o cambia también. Simultáneamente, la diferencia entre este artefacto y un ente natural es que, mientras este último tiene la potencialidad de ser un esto determinado antes de que la forma se realice en la materia, no sucede lo mismo con el primero. Una semilla de árbol es un árbol en potencia, aun antes de ser un árbol, pero no sucede lo mismo con la madera de la cama antes de que el carpintero use esa madera para construir la cama.

$24 \quad$ Para ver el parangón que se puede trazar con la Física, véase Física II 1,198 b 8 y ss. 
Para Aristoteles "no pretende ser fin cualquier término último, sino solo lo mejor". ${ }^{25}$ Esta tesis que es formulada en extenso en la Física es expuesta con cierto detalle en este fragmento. De los distintos pasajes y fragmentos trabajados puede concluirse que desde la perspectiva aristotélica "phýsis no tiene sólo el sentido de arkhé, sino que representa el cumplimiento de un orden teleológico" (Van der Meeren, 2011, p. 30). Si bien la naturaleza de las cosas está determinada desde su génesis, ésta no está realizada desde el principio, sino que debe actualizarse. Este proceso de autorrealización es, como vimos en el apartado anterior, la realización de la forma, esto es, la esencia de la cosa.

Es evidente que Simplicio no se detiene en el análisis de esta tesis, pues su objetivo central es hablar sobre lo divino y su naturaleza. Las cosas sujetas al devenir son presentadas como un contrapunto respecto de esta entidad, que, según algunos intérpretes, es el motor inmóvil. ${ }^{26}$ Independientemente de esto, el análisis del pasaje de Sobre el cielo, a la luz de su comentario de la Física, nos induce a pensar que, al hablar del principio interno de movimiento, Simplicio tiene que estar pensando en la noción de phýsis aristotélica y su conexión con la forma. Como consecuencia de esto, al hablar de la causa final en este fragmento, Simplicio no sólo podría estar haciendo referencia al motor inmóvil, tal como se podría desprender de la última parte del fragmento cuando habla de lo divino, sino también a la forma como causa final y, por lo tanto, a la naturaleza.

En la Física II 7 198a 34- 198b 3, Aristóteles sostiene:

Pero los principios del movimiento natural son de dos tipos: uno de ellos no es físico, pues no tiene principio de movimiento en sí mismo. Y si hay algo que mueve sin moverse, será de esta clase, tal como el $<$ motor $>$ absolutamente inmóvil y primero de todo, y también el "que és" y la forma. Ello es el fin, o sea, es causa final (trad. Boeri). ${ }^{27}$

$25 \quad$ Física II 2, 194a, 32-33.

$26 \quad$ Entre los que sostienen esta tesis cabe citar a Untersteiner, 1963, p. XIV; Chroust, 1975, pp. 553-569; Dumoulin, 1981, pp. $44-75$ y Berti 1997, p.289.Para esta cuestión véase también Guthrie ,1933, pp. 162-171 y Chroust 1972.

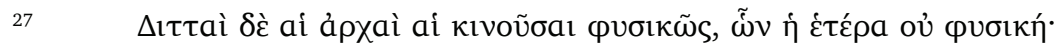

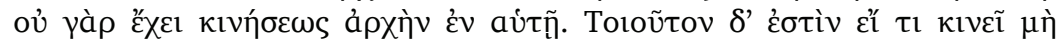

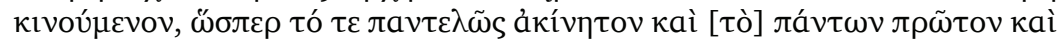

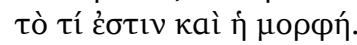


Desde la perspectiva del Estagirita, tanto el primer motor inmóvil como la forma son principio de movimiento, que se caracterizan por no requerir de un principio ulterior que los explique. El sentido de las palabras de Aristóteles puede entenderse a la luz de Metafísica III 4, 999b 1 y ss. Allí, en el contexto de la octava aporía Aristóteles analiza las consecuencias que se desprenden de postular solamente la existencia de los particulares sensibles. La conclusión que cree extraer Aristóteles es que si solo existiese este tipo de entidades y no hubiese nada que fuese inmóvil y eterno, no sería posible la generación. Ahora bien, los individuales sensibles están sujetos a generación y corrupción, razón por la cual, si no existiese lo inmóvil y eterno, tampoco podría existir este tipo de cosas.

Al interpretar el pasaje de la Física arriba citado, Simplicio señala que, al referirse al "qué es" y la forma como un principio absolutamente inmóvil, Aristóteles está pensando en la forma como fin y "aquello para lo cual", pues "el fin debe ser invariable y determinado, mientras que lo que cambia cambia por un fin" (Simplicio, comentario a la Física 367. 1). La forma, en tanto causa final, es aquello que "promueve" el cambio, permaneciendo invariable. Es eterna, pues es imposible que las cosas sujetas al devenir surjan de lo que no es. Finalmente constituye lo mejor para la cosa respecto de la cual es forma, pues "el fin de cualquier cosa es siempre mejor que ella, puesto que todas las cosas generadas se generan con vistas a un fin" (Protréptico fragmento 17, trad. Vallejo Campos.)

En Física I 9, 192a 20-22, Aristóteles afirma:

No es posible que una misma forma aspire a sí misma ya que <en tal caso $>$ no carece de nada, ni tampoco que aspire a ella $<$ la forma $>$ contraria, pues los contrarios son causa de destrucción recíproca (trad. Boeri). ${ }^{28}$

Las palabras de Aristóteles en este pasaje parecen ir en paralelo con lo afirmado por Simplicio en el fragmento 16 de Sobre la filosofía, cuando habla de lo divino y sostiene que este no aspira a nada, pues no hay nada que sea mejor que él. En

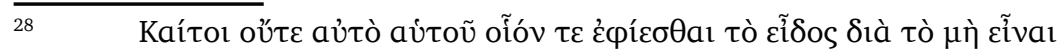

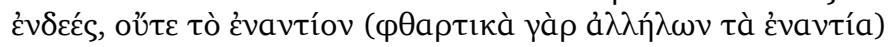


este punto debemos tener presente que el pasaje citado corresponde a los últimos párrafos del primer libro de la Física. La problemática de este libro es la naturaleza y número de los principios. En función de esta problemática Aristóteles explora las opiniones de sus predecesores. Una de ellas, es la de Parménides. En contra de Parménides, Aristóteles negará que solo pueda haber una única naturaleza, es decir, un único ser, pues de ser así este no podría ser principio o causa (Física I 2, 185a1ss). No obstante, Aristóteles le concede a Parménides en el comienzo del capítulo 9 de la Física que es imposible que algo se genere a partir de lo que no es. Dado que la generación es un movimiento del no ser al ser y que dicho movimiento es innegable, debe haber algo imperecedero y eterno que sea principio de movimiento. Esto no puede ser la privación porque la privación es lo opuesto a lo imperecedero, eterno y divino. Tampoco puede ser la materia, pues la materia aspira por naturaleza a lo eterno e invariable. Lo único que puede cumplir este requisito es la forma, porque la forma no puede aspirar a otra cosa que no sea ella misma. Si bien en el capítulo 9 Aristóteles sostiene que la materia es ingenerada (I 9, 192a28), pues de generarse sería necesario considerar la existencia de un sustrato, e imperecedera, pues lo que se corrompe en ella es privación (I 9, 192a26-27), también admite que es potencialidad (II 1, 193b68). Por este motivo, junto a la materia debe postularse la forma que tiene la particularidad de ser eterna, incorruptible, pero en acto. En el Comentario a la Física 250. 10, Simplicio interpreta el texto en esta misma línea, aunque también deja abierta la posibilidad de que lo calificado de divino, bueno y aquello que debe ser perseguido sea la forma primera, separada, a la que suele llamársele noûs y causa primera (250. 14-15), esto es, el primer motor inmóvil. Lo relevante es que, desde su perspectiva (250. 22- ss.), las entidades compuestas < de materia y forma $>$, esto es las entidades sensibles, no solo dependen de la forma y se conservan por ella, sino que también se esfuerzan por alcanzarla, esto es, tienden a ella, no como un deseo (órexis), ya que este solo existe en las entidades que poseen alma, sino como un esforzarse (éphesis). ${ }^{29}$

$29 \quad$ Otros de los puntos relevantes es que en su comentario Simplicio califica a la naturaleza como divina: Өcíov (comentario a la Física 250. 15). Si 
Teniendo esto como telón de fondo, y partiendo de la tesis presentada en la segunda parte de este trabajo, según la cual la forma es phýsis en sentido propio, debemos admitir que en el fragmento 16 se presenta un esbozo de la concepción teleológica de la naturaleza. Si bien queda pendiente analizar si en este fragmento está bosquejada de la concepción del motor inmóvil, tal como lo interpretan algunos estudiosos, creemos que leer el fragmento a la luz de la noción de phýsis presentada en Física II vuelve inteligible el texto y nos permite explicar por qué en esta última obra el Estagirita alude a Sobre la filosofía.

\section{Conclusión}

En el presente trabajo nos hemos centrado en las nociones de naturaleza y de finalidad tomando como punto de partida la Física y Sobre la filosofía. Para ello, hemos limitado nuestro análisis al libro II de la Física especialmente al pasaje II 2 194a26-36, en el cual Aristóteles realiza una remisión a su obra fragmentaria: Sobre la filosofía. El análisis de la noción de phýsis en esta última obra nos llevó a centrarnos básicamente en dos fragmentos: el 8b y el 16. Si bien en la primera parte examinamos de manera sucinta los fragmentos en los cuales aparece la noción de phýsis, hemos considerado que en estos dos últimos fragmentos se habría desarrollado de manera explícita o implícita las premisas formuladas en el pasaje II 2 194a26-36 de la Física. Para ello y en función del carácter fragmentario de Sobre la filosofía, hemos realizado un análisis de estos fragmentos teniendo como telón de fondo los comentarios de la Física de Filópono y Simplicio, dos de los comentadores por cuyo medio nos han llegado los extractos de la obra perdida de Aristóteles.

extrapolamos esta caracterización de la naturaleza al fragmento 16 de Sobre la filosofía, podemos concluir que la lectura según la cual el referente de lo divino, eterno e imperecedero debe ser el motor inmóvil es una, pero no la única manera de entender el texto. una lectura más rica del texto implica suponer que en este extracto de la obra pueden estar conviviendo ambas interpretaciones: aquella que sostiene la referencia al motor inmóvil y esta otra que sugiere la alusión a la concepción teleológica de la naturaleza. 
El examen realizado nos permitió concluir que, si bien en el fragmento 8b no hay una relación explícita entre ousía y phýsis, ambas nociones tienden a ser equiparadas en la estructura profunda del texto. Esto se desprende de que, ya sea cuando habla de la ousía de las cosas como cuando se refiere a la phýsis, Filópono parece estar refiriéndose a la esencia o configuración conceptual de las cosas, esto es, aquello que, debido a que es la causa de que las cosas sean lo que son, proporciona un verdadero conocimiento.

Simultáneamente establecimos que en el fragmento 8b, al igual que en Física II, para Aristóteles la phýsis es principio de movimiento interno. Esto se infiere del carácter demiúrgico que Filópono le atribuye a la noción aristotélica de phýsis. Cabe destacarse que dicha caracterización de la phýsis aparece atestiguada en algunos de los tratados biológicos, como Partes de los animales. De la lectura del fragmento $8 \mathrm{~b}$ se puede concluir que la naturaleza es identificada con el proceso y el fin por el cual las cosas se realizan. Es causa motriz y final de las cosas. Esto mismo aparece atestiguado en el fragmento 9 de Sobre la filosofía, en los comentarios de la Física de Filópono y de Simplicio, a la vez que aparece desarrollado claramente en los pasajes analizados de la Física de Aristóteles.

En la tercera parte, hemos intentado demostrar que en el fragmento 16 de Sobre la filosofía Simplicio desarrolla la concepción teleológica de la naturaleza atribuida a Aristóteles. Al igual que en la Física (II 2 194a26-36), Simplicio considera que en Sobre la filosofía el Estagirita no solo habría sostenido que las cosas existen conforme a un fin, sino que este fin es lo mejor. A lo largo de este apartado pudimos constatar que las tesis adjudicadas a Aristóteles sobre lo que es mejor, y divino y por sí son consistentes con la caracterización de la forma rastreable en la Física y en el comentario de Simplicio de esta misma obra. Como consecuencia de esto, en este fragmento Simplicio está sistematizando la concepción aristotélica de la forma como fin y, por ende, desarrollando la concepción teleológica de la phýsis, ya que la forma es naturaleza en sentido propio. 
Esta unidad en cuanto a las concepciones tratadas permite que Aristóteles remita a Sobre la filosofía en el segundo libro de la Física. Se debe tener en cuenta, por otra parte, que Sobre la filosofía es un texto desconocido para nosotros, pero era un texto de difusión de las concepciones aristotélicas. Como consecuencia de esto, es esperable que aquellos que eran contemporáneos de Aristóteles o que accedieron a sus enseñanzas conocieran las tesis defendidas en esta obra. Por tal motivo. podían relacionar las teorías desarrolladas en este escrito con las que Aristóteles estaba exponiendo en los lógoi physicoí sin necesidad de mayores aclaraciones. Esto vuelve comprensible por qué Aristóteles dice que "esta cuestión ya la hemos tratado en Sobre la filosofía" (Física II 2, 194a36), sin tener que aclarar específicamente a qué se estaba refiriendo. La lectura de los fragmentos de Sobre la filosofía, en los cuales aparecen las nociones de phýsis y de finalidad, nos permite concluir que dicha obra realmente debió haber podido echar luz a muchas de las tesis mencionadas y desarrolladas en la Física. La historia de la trasmisión de los textos ha generado el efecto contrario: el carácter fragmentario de Sobre la filosofía hace que nosotros debamos valernos de su mención en la Física, para, a partir de este último texto, poder entender algunos de los conceptos desarrollados en el primero que, por haberse perdido, nos resulta enigmático.

\section{Referências}

AUBENQUE, P., El problema del ser en Aristóteles, trad. cast. de V. Peña, Madrid: Escolar y Mayor Editores, 2008 [1963].

BALTUSEEN, H., Philosophy and Exegesis in Simplicius. The Methodology of a Commentator, London: Bloomsbury, 2008.

BERTI, E., La filosofia del "primo" Aristotele, Milano: Centro di Richerche di Metafisica dell' Università Cattolica del Sacro Cuore, 1997 [1962].

BERTI. E.- ROSSITTO. C., Aristotele Il libro primo della Metafisica, introduzione, traduzione e commento, Milano: Biblioteca Universitaria Rizzoli, 2002 [1973].

BOERI, M., Aristóteles, Física, libros I y II, introducción, traducción y notas, Buenos Aires: Biblos, 1993. 
BONITZ, H., Index Aristotelicus, Berlin : Reimer, 1870.

CALVO MARTÍNEZ, T., Aristóteles, Acerca del alma, introducción, traducción y notas, Madrid: Gredos, 1983 [1978].

CALVO MARTÍNEZ, T., Aristóteles, Metafísica, introducción, traducción y notas, Madrid: Gredos, 2007.

CHARLTON, W., Aristotle's Physics I- II, Introduction and commentary, New York: Clarendon Press, 2006.

CHROUST, A. H., A Tentative Outline for a Possible Reconstruction of Aristotle's Lost Dialogue On Philosophy, L' Antiquité Classique, 44, Fasc. 2, 1975, pp. 553-569.

CHROUST, A. H., "Mystical Revelation" and "Rational Theology", in Aristotle's On Philosophy", Tijdschrift voor Filosofie, 34ste Jaarg., Nr. 3, 1972, pp. 500-512.

DIELS, H. (ed.), Simplicii in Aristotelis Physicorum Libros Quattuor Priores Commentaria, Berlin: Berolini, 1882.

DUMOULIN, B., Recherches sur le premier Aristote, Paris : Vrin, 1981.

DÜRING, I., Aristóteles. Exposición e interpretación de su pensamiento, trad. Cast. de B Navarro, México: Universidad Nacional Autónoma de México, 1990 [1966].

DÜRING, I., Aristotle's Protrepticus, An Attempt at Reconstruction, Göteborg: Almqvist \& Wiksell, 1961.

Echandía, G., Aristóteles, Física, introducción, traducción y notas, Madrid: Gredos, 1995.

FLEET, B., Simplicius, On Aristotle Physics 2 Translated and commentary, London: Bloomsbury, 2014.

GIARDINA, G. R., Giovanni Filopono matematico. Tra neopitagorismo e neoplatonismo. Commentario alla Introduzione aritmetica di Nicomaco di Gerasa Introduzione, testo, traduzione e note, Catania: CUECM, 1999.

GIGON, O., Aristotelis Opera, vol. III, Librorum Deperditorum Fragmenta, Berlin: Walter De Gruyter, 1987.

GOLITSIS P., Les Commentaires de Simplicius et de Jean Philopon à la Physique d'Aristote Tradition et Innovation, New York: Walter De Gruyter 2008.

GUTHRIE, W. K. C., The development of Aristotle's Theology, Class. Quarterly 27, 1933, pp. 162-171.

Jaeger, W., Aristóteles. Bases para la historia de su desarrollo, trad. cast. de J. Xirau y W. Roce, México: Fondo de Cultura Económica, [1923].

LENNOX, J. G., Aristotle's Philosophy of Biology: Studies in the Origins of Life Science, Cambridge: Cambridge University Press, 2001. 
MADISON, R. D., First Philosophy: Aristotle's Concept of Metaphysics (diss.), Chicago: Loyola University Chicago, 2008.

Osborne, C., Philoponus, On Aristotle Physics 1. 1-3 Translated and commentary, London: Bloomsbury, 2006.

QUARANTOTTO, D., Causa finale, sostanza, essenza in Aristotele. Saggio sulla struttura dei processi teleologici naturali e sulla funzione del telos, Napoli: Bibliopolis, 2002.

RADICE, R. (ed.), Lexicon III. Aristoteles, 2 vols., Milano: Biblia, 2005.

RADICE, R., Aristotele, Fisica, introduzione, traduzione e commento, Milano: Bompiani, 2011.

ROSE, V., Aristotelis qui ferebantur Librorum Fragmenta, Stuttgart: Teubner, 1966 [1886].

ROSS, W. D, Aristotle's Physics, Introduction and commentary, Oxford: Clarendon Press, 1936.

ROSS, W. D., Aristotelis Dialogorum Fragmenta, Oxford: Clarendon Press, 1964.

SÁNCHEZ-ESCARICHE, E. J., Aristóteles, Partes de los animales, introducción, traducción y notas, Madrid: Gredos, 2000.

TODD, R., Themistius, On Aristotle Physics 1-3 Translated and commentary, London: Bloomsbury, 2012.

UNTERSTEINER M., Aristotele, Della filosofia, Introduccione, testo, traduzione e comment esegetico, Roma: Edizioni di Storia e Letteratura, 1963.

VALLEJO CAMPOS, A., Aristóteles, Fragmentos, introducción, traducción y notas, Madrid: Gredos, 2005.

VAN DER MEEREN, S., Exhortation à la philosophie: Le dossier grec, Aristote, Paris: Les Belles Lettres, 2011.

VITELLI, H. (ed), Philoponi in Aristotelis Physicorum Libros Quattuor Priores Commentaria, Berlin: Berolini, 1887.

ZANATTA, M., Aristotele, I Dialoghi, introduzione, traduzione e commento, Milano: Biblioteca Universitaria Rizzoli, 2008. 